\title{
RESULTS OF THE APT RF POWER COUPLER DEVELOPMENT FOR SUPERCONDUCTING LINACS*
}

\author{
E. N. Schmierer, W. B. Haynes, F. L. Krawczyk, D. C. Gautier, J. G. Gioia, M. A. Madrid, R. E. \\ Lujan, K. C. D. Chan, D. Schrage, B. G. Smith, J. Waynert; LANL, Los Alamos, NM 87545, USA \\ B. Rusnak; Lawrence Livermore National Laboratory, Livermore, CA 94550, USA
}

\begin{abstract}
For the new baseline APT (Accelerator Production of Tritium) linac design, the power couplers are required to transmit $420 \mathrm{~kW}$ of CW RF power to the superconducting cavities at $700 \mathrm{MHz}$. These couplers consist of an airside waveguide-to-coax transition, an air/vacuum break made by two planar, coaxial windows, and a vacuum-side coaxial antenna section. The coaxial antenna allows adjustability of the RF matching to the superconducting cavities. Design, fabrication, and testing of the power coupler/window occurred over the last four years, and room temperature testing of the prototype design is complete. Coupler/window assemblies have transmitted power to $1 \mathrm{MW}, \mathrm{CW}$ and have handled full reflected 850 $\mathrm{kW}$, CW over a limited standing-wave phase range. Couplers were tested with a portion of the outer conductor cooled by liquid nitrogen to study the effects of condensed gases. Final results, conclusions, and lessons learned about the coupler design, fabrication, and testing will be discussed.
\end{abstract}

\section{OVERVIEW AND REQUIREMENTS}

The power coupler was one of the challenges for the Accelerator Production of Tritium (APT) linac, which has a high-energy superconducting (SC) section spanning 210-1030 MeV [1]. Due to the $100 \mathrm{~mA} \mathrm{p}{ }^{+}$current, a large amount of continuous wave $(\mathrm{CW})$ radio frequency (RF) power must be transmitted into the SC cavities through the input power coupler. In 1997, the coupler requirement of $210 \mathrm{~kW}, \mathrm{CW}$ (at $700 \mathrm{MHz}$ ) was chosen for the APT couplers as a reasonable extrapolation of the technology. Later, due to testing results, this was increased to $420 \mathrm{~kW}$, CW requiring only one coupler per cavity. Multipacting and window failure concerns governed the design features of the coupler/window assembly. Figure 1 shows the APT coupler layout.

\section{ASSEMBLY DESIGN}

\subsection{Coupler \& RF Window Assembly Design}

The assembly consists of four separable components. These are the RF window assembly, outer conductor (OC), inner conductor (IC), and the thermal intercept. The RF window assembly consists of a WR 1500 waveguide-to-coaxial conductor (50 Ohm, $\phi 152-\mathrm{mm})$ tee-

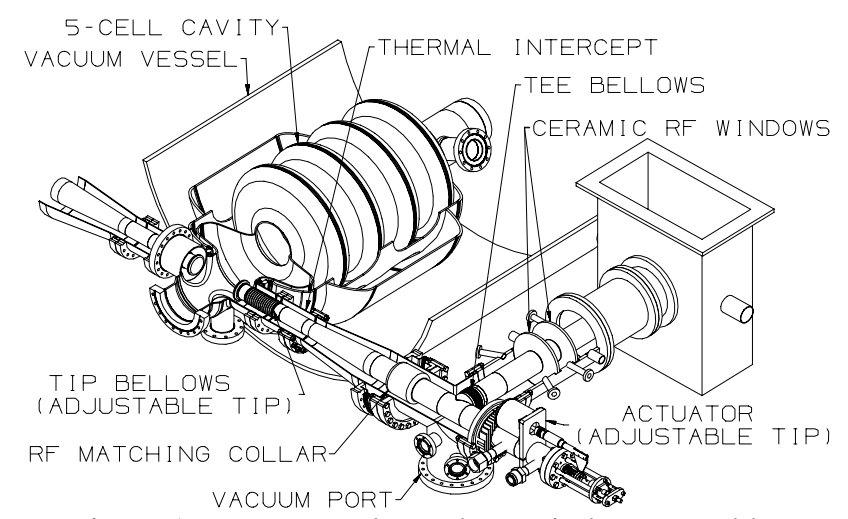

Figure 1: Power coupler and RF window assembly.

bar transition containing the dual, ceramic windows. The power coupler (IC, OC, and thermal intercept) interfaces the RF window assembly at the tee bellows. It contains a 4-way, $\phi 152-m m$ coaxial tee ( $1 / 4$-wave stub opposite the cavity, vacuum pump port directly under the tee, window connection, and the cavity connection that tapers to $\phi 100$ $\mathrm{mm}$ through a distance of $207-\mathrm{mm}$ at the thermal intercept). The matching collar and $1 / 4$-wave stub match the RF impedance. A fixed-tip IC and an adjustable-tip IC design were produced. Additional information about the mechanical and RF design is in another reference [2].

\subsection{Analysis \& Verification}

The thermal design of the power coupler is addressed in other references [2][3]. To verify the cryogenic heat leaks from the power coupler, the cryogenic test rig (CTR) was built. The results were found to be in good agreement with the thermal model. However, certain enhancements had to be made to the model. The thermal interface impedance at each Conflat vacuum flange on the OC was found to be important in matching the predicted and measured temperature distributions. This added two thermal resistances to the model. The measured heat leak is largely dependent on the low temperature intercept temperature, which in a cryomodule will vary from one coupler to the next because they are in series.

The antenna tip movement of the IC relative to the cavity due to thermally induced displacement and dynamic motion was analyzed [2]. In general, their effect on the external-Q should be considered if implementing a fixed-tip power coupler design.

\footnotetext{
* Supported by US DOE, NNSA and the Office of Nuclear Energy, Science and Technology
} 


\subsection{Fabrication}

The quantity of coupler/windows required for the APT linac is 242 , with one for each SC cavity. Separate vendors fabricated the individual prototype components. Ten OC's, 8 IC's, 10 RF window assemblies, and 7 thermal intercepts were fabricated. The major issue with fabrication was procurement of bellows for the inner conductor in the small quantities of custom geometry required. A manufacturing study was performed on the prototype coupler/window assembly design [4].

\section{HIGH POWER TESTING}

\subsection{Test Stand \& Procedures}

Power coupler/window assemblies were tested on the Room Temperature Test Bed (RTTB) [5]. Up to $1 \mathrm{MW}$, CW RF power is available from a 700-MHz klystron. Two power coupler/window assembly pairs are coupled by a pillbox cavity in the $\mathrm{TM}_{010}$ mode.

Before testing, the inner conductors and outer conductors received either a Citronox degreasing or were wiped with a lint-free cloth and methanol. The RF window assemblies were installed on the test stand directly from their crates, and were removed from the stand only once during testing to be grit-blasted.

Prior to high power testing, all the component sets were tested at low power using a HP 8753E network analyzer. Measurements were taken from the waveguide of the input RF window assembly to the output RF window assembly waveguide using WR1500 waveguide to BNC adapters. With this setup, the maximum VSWR measured for all combinations of components was less than the required 1.04. Figure 2 is a typical transmission plot for a set of components.

\subsection{High-Power Tests and Results}

Four general tests were performed: (1) transmittedpower, (2) totally-reflected power, (3) condensed-gas effects, and (4) longer-term steady power transmission.

During transmitted-power capability tests, RF power was simply transmitted from the klystron, through the couplers, and into the RF load. This included the conditioning phase, where the power level was raised in steps to reach the desired power level. During this, the pressure was kept below $5 \times 10^{-6}$ torr. Results from the first fixed-tip power couplers tested are in another reference [6], as are results from the adjustable-tip coupler transmission testing [7]. Both designs reached $1 \mathrm{MW}$, $\mathrm{CW}$, with the klystron dictating maximum power levels.

There appeared to be a correlation between the residual gas magnitudes and conditioning time rather than conditioning rate. The time when $\mathrm{H}_{2}$ became the dominant residual gas was consistent [7]. During steadystate testing the majority of the interruptions in power were klystron false positive trips and not arcing.

For reflected-power testing, a "sliding short" allowed movement of the standing-wave maxima and minima in $\lambda / 16$ increments. The tests reached $950 \mathrm{~kW}, \mathrm{CW}$ for a sliding-short position corresponding to full current operation. For all other short positions, we reach a power level of $550 \mathrm{~kW}, \mathrm{CW}$ and a power level of $850 \mathrm{~kW}$ at a duty cycle of $50 \%$. Limitations were due to maximum temperature constraints on the RF window housings [6].

To investigate the condensed-gas effects, we cooled the outer conductor by passing liquid nitrogen through the passages of the thermal intercept [7]. Based on the residual gases, water vapor and $\mathrm{CO}_{2}$ were expected to condense during these tests. A surface temperature of $\sim 30$ $\mathrm{K}$ would be required to condense other gases. Therefore, it was deemed that testing with a colder OC wouldn't add significant information about the coupler performance. This method was sufficient for determining multipacting effects in the CERN LEP2 power coupler [8].

Longer term testing was performed at $420 \mathrm{~kW}$, which had recently become the baseline design power requirement. During this testing, a certain power level was obtained and then maintained for a given amount of testing time. The longest run was 95 hours at $420 \mathrm{~kW}$. During initial conditioning the pressure range is $1 \times 10^{-7}$ $5 \times 10^{-6}$ torr. With RF on after conditioning it resides in the $1 \times 10^{-8}-1 \times 10^{-7}$ torr range. The pressure is typically a factor of five less with the RF off.

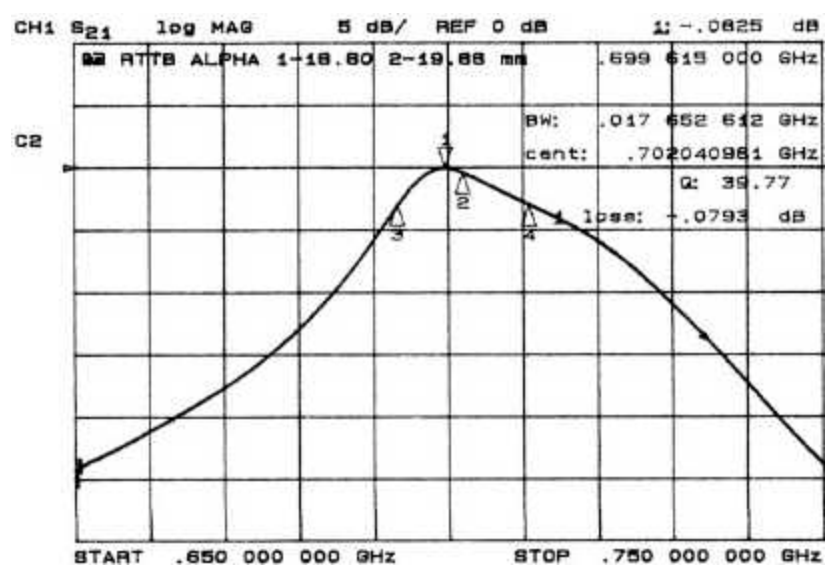

Figure 2: Typical transmission of a set of components encompassing an assembly pair and cavity on the RTTB.

\section{OBSERVATIONS DURING TESTING}

\subsection{Tip Bellows Failure}

During testing of adjustable-tip IC's on the RTTB, two failures of tip bellows occurred. Material analysis performed on the failed bellows determined the bellows material over-aged. This reduced the yield strength below the high stresses caused by the thermally induced displacements, allowing failure along the grain boundaries. The high temperatures $\left(\sim 400{ }^{\circ} \mathrm{C}\right)$ that the IC bellows experienced were due to cooling with air instead of $\mathrm{He}$ and testing at power levels significantly higher than $500 \mathrm{~kW}, \mathrm{CW}(500 \mathrm{~kW}, \mathrm{CW}$ was the thermal/mechanical design power level). Reengineering of the tip region and/or $\mathrm{He}$ coolant would be required for sustained operation of the adjustable IC over $500 \mathrm{~kW}, \mathrm{CW}$. 


\subsection{Arcing}

During conditioning, arcing occurred on the vacuum side of the windows. After a power level had been conditioned to, no more arcs were seen below this power level. Arc rates varied between component sets but generally increased in the $200-350 \mathrm{~kW}$ power range. This corresponds to the regions of heightened vacuum activity in the testing (see section 4.5). Anomalous arcing occurred in two instances due to a poor connection of the receiver cup to the IC of the RF window assembly.

\subsection{Electron Etching}

All IC's tested had evidence of electron activity on their surface. These patterns varied in concentration and position with each test as well as with power level. At power levels between 210 and $500 \mathrm{~kW}$, they were typically only shallow, dendrical patterns. Above 500 $\mathrm{kW}$, the patterns were deeper and more concentrated in a single spot. The occurrences of the electronic etching didn't correspond to arc measurements, nor did it affect coupler operation. It is believed that this was due to surface condition, as it didn't occur on electroplated IC's at $420 \mathrm{~kW}$. There is also some evidence that it occurs only during conditioning and is not a continual process.

\subsection{RF Window Assemblies}

The total hours of operation of the window assemblies above $210 \mathrm{~kW}$ was estimated at 530 hours. No problems were encountered with RF transmission or cooling of the window assemblies at or below $420 \mathrm{~kW}$. At power levels over $\sim 450 \mathrm{~kW}$ the output vacuum side window would glow orange around the braze joint of the inner conductor. This ceased after grit-blasting of the two windows. At power levels of $\sim 850 \mathrm{~kW}$ and above, the vacuum side windows glowed blue over the surface. This was not reconfirmed following grit-blasting. The requirement to rotate the RF window assembly during installation led to damaging two of three units tested and damage to one IC.

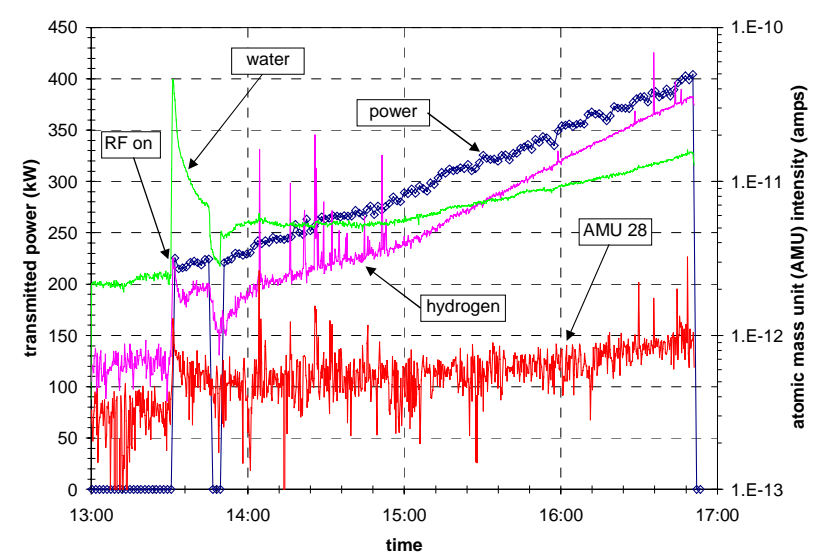

Figure 4: Residual gas magnitude (right axis) and power level (left axis) versus time during a room temperature power level sweep to look for multipacting power levels.

\subsection{Multipacting}

There were no hard multipacting barriers encountered during conditioning to $1 \mathrm{MW}$, which typically took 24 hrs. There were some indications from erratic vacuum activity in the $250-350 \mathrm{~kW}$ range. To quantify this, the power level was slowly swept up and down between 200 and $400 \mathrm{~kW}$ at room temperature and with a portion of the outer conductor cold. One example of this for room temperature is shown in Figure 4. No specific power level could be discerned, and testing cold only slightly enhanced the same affects. We believe the lack of major multipacting affects is mostly due to the excellent vacuum pumping near the window.

\section{DEVELOPMENT SUMMARY}

- APT power coupler and RF window assembly development occurred from 1997 to 2000.

- The ability to fabricate the prototype coupler/window assembly in small quantities was demonstrated with no major difficulties.

- Performance in terms of RF power capability was demonstrated by tests of both fixed and adjustable coupling power couplers up to $1 \mathrm{MW}, \mathrm{CW}$ travelingwave and $850 \mathrm{~kW}$, CW standing-wave power.

- Only minor indications of multipacting were seen during conditioning, this is attributed to the coax sizing and excellent pumping near the window.

\section{REFERENCES}

[1] G. P. Lawrence, "High-Power Proton Linac for APT; Status Of Design And Development," LINAC98 Proceedings (1998).

[2] E. N. Schmierer, et. al., "Development of the SCRF Power Coupler for the APT Accelerator," PAC99 Proceedings (1999).

[3] J. A. Waynert \& F. C. Prenger, "A Thermal Analysis and Optimization of the APT $210 \mathrm{~kW}$ Power Coupler," LINAC 98 Proceedings (1998).

[4] LANL Report: LA-UR-01-0030, “APT ED\&D Coupler/Window Manufacturability Assessment: Final Report," December 2000.

[5] J. Gioia, et al., "A Room Temperature Test Bed for Evaluating $700-\mathrm{MHz}$ RF Windows and Power Couplers for the Superconducting Cavities of the APT Linac," PAC99 Proceedings (1999).

[6] E. N. Schmierer, et al., "Testing Status of the Superconducting RF Power Coupler for the APT Accelerator", 9 ${ }^{\text {th }}$ RF Superconductivity Workshop Proceedings (1999).

[7] E. N. Schmierer, et al., "High-Power Testing of the APT Power Coupler", LINAC 2000 Proceedings (2000).

[8] Haebel, E., et. al., "Gas condensation on cold surfaces, a source of multipacting discharges in the LEP2 power coupler," 7th RF Superconductivity Workshop Proceedings (1995). 